ARTIGOS / ARTICLES

\title{
Quantificação de Conídios de Pyricularia grisea no Plantio Direto e Convencional de Arroz de Terras Altas*
}

\author{
Gisele B. da Silva ${ }^{1} \&$ Anne S. Prabhu ${ }^{2}$ \\ 'Escola de agronomia Universidade Federal de Goiás, Cx. Postal 131, CEP 74001-970, Goiânia, GO, \\ e-mail: gibarata@bol.com.br; 'Embrapa-Centro Nacional de Pesquisa de Arroz e Feijão, Cx. Postal 179, \\ CEP 75375-000, Santo Antônio de Goiás, GO, e-mail: prabhu@ @npaf.embrapa.br
}

(Aceito para publicação em 17/08/2005)

Autor para correspondência: Gisele Barata da Silva

SILVA, G.B. \& PRABHU, A.S. Quantificação de conídios de Pyricularia grisea no plantio direto e convencional de arroz de terras altas. Fitopatologia Brasileira 30:569-573. 2005.

\section{RESUMO}

Foi estudada a liberação de conídios de Pyricularia grisea no plantio convencional (PC) e direto (PD) de arroz (Oryza sativa) de terras altas, nas fases de desenvolvimento vegetativo e emissão de panículas nos experimentos de campo realizados em dois anos (1998/2000). As coletas de conídios de P. grisea foram realizadas com as armadilhas volumétricas Rotorod sampler. Objetivando quantificar os conídios viáveis e com potencial para causar infecção em folhas novas foram também utilizadas bandejas com plantas de arroz com 25 dias de idade das cultivares Carajás e Primavera expostas no campo, como armadilhas vivas. Na safra 1998/1999, o número de conídios de $P$. grisea aumentou linearmente com o tempo, entre o estádio de grão pastoso e maduro. Na safra de 1999/2000, a quantidade de conídios coletada aumentou de maneira exponencial, iniciando ao final do estádio emborrachamento até na fase de grão semimaduro. O número de conídios coletados com a armadilha volumétrica diminuiu exponencialmente com o aumento da precipitação pluviométrica, assim como, reduziu a severidade da brusone nas plantas da armadilha viva tanto para a cultivar Carajás como para Primavera. A produção e a liberação de conídios foi menor no plantio direto tanto na fase vegetativa como durante o enchimento dos grãos nas panículas.

Palavras-chave adicionais: Magnaporthe grisea, Oryza sativa, epidemiologia, armadilhas de esporos, sistema de cultivo.

\begin{abstract}
Quantification of conidia of Pyricularia grisea in rice using direct and conventional drilling under upland conditions The conidial release of Pyricularia grisea in upland rice (Oryza sativa) in vegetative and panicle developmental phases was studied in field experiments, under both conventional planting and direct drilling methods, over a period of two years (1998/2000). The conidia of $P$. grisea were collected with a volumetric Rotorod spore sampler. For quantifying viable conidia that posseses potential for causing infection in new leaves, plastic trays containing 25 -day old rice plants of cultivars Carajas and Primavera were exposed in the field as live spore traps. The increase in conidial production and release was linear with time from dough to mature growth stages, during the 1998/99 rice growing season. In 1999/2000, the quantity of conidia increased exponentially starting from terminal booting until semimature growth stages. The number of conidia colleted with the volumetric spore sampler decreased in an exponential manner with an increase in the amount of rainfall, with reduction of leaf blast severity in live traps in cultivars Carajas and Primavera. Conidial production and release was lower under direct drilling than in the conventional method of planting in both the vegetative and grain formation phases of panicle.
\end{abstract}

Additional keywords: Magnaporthe grisea, Oryza sativa, epidemiology, spore traps, tillage system.

\section{INTRODUÇÃO}

O agente causal da brusone [Pyricularia grisea (Cooke) Sacc. (= Magnaporthe grisea (Hebert) Barr.] é perpetuado assexualmente através de conídios. Nas cultivares suscetíveis a quantidade de lesões esporulativas depende das práticas culturais adotadas e muitos fatores afetam a produção

*Parte da dissertação da primeira autora apresentada na UFG (2000) e a liberação de conídios tais como temperatura, precipitação pluviométrica, umidade, vento e a resistência do hospedeiro. A esporulação aumenta quando a umidade relativa é superior a $93 \%$ e não ocorre abaixo de $89 \%$, enquanto que a temperatura ideal varia entre 25 e $28{ }^{\circ} \mathrm{C}$. Sob condições ideais, alta taxa de produção de conídios ocorre entre três e oito dias após o aparecimento da lesão e estende-se por mais de 20 dias (Kim, 1994). As lesões mantêm sua capacidade de esporulação por períodos mais prolongados quando a 
temperatura varia entre 16 e $24^{\circ} \mathrm{C}$, do que com temperatura constante de $28{ }^{\circ} \mathrm{C}$. A produção e a liberação de conídios atingem o máximo entre meia-noite e $6 \mathrm{~h}$ e são disseminados pelo vento ou chuvas. (Webster \& Gunell, 1992). Aproximadamente 8 milhões de conídios $/ \mathrm{cm}^{2}$ podem ser produzidos na superfície das folhas infetadas. Os conídios do agente causal da brusone são comumente disseminados num raio de $230 \mathrm{~m}$ da fonte de inóculo (Kingsolver et al., 1984). As chuvas lavam os conídios das plantas, reduzindo a quantidade de inóculo e, em dias chuvosos, a disseminação de conídios é menor. Precipitações com intensidade superior a 3,5 mm/dia são importantes na redução da doença (Kim, 1994). A incidência de brusone em arroz (Oryza sativa L.) de terras altas, em anos chuvosos, tem sido menor que em anos com deficiência hídrica. No Brasil Central, a alta severidade da brusone é favorecida por oscilações de temperatura entre o dia e a noite, resultando em períodos prolongados de orvalho (Prabhu \& Morais, 1986).

No plantio direto (PD), a amplitude de temperatura e a temperatura abaixo da camada da palha são inferiores àquelas de plantios convencionais (Gassen \& Gassen, 1996), podendo retardar o desenvolvimento da brusone. Além da temperatura, outra variável climática de grande importância para o desenvolvimento das doenças é a duração do período de molhamento foliar, que nesse sistema prolonga-se, em média, por 1 a 2 h em relação a solos descobertos (Fernandes, 1997). Não há informações quanto à influência do PD sobre a incidência da brusone para minimizar seu efeito na produtividade e qualidade dos grãos através de medidas adequadas de controle. O sucesso do manejo depende da disponibilidade de conhecimentos sobre diferentes aspectos no desenvolvimento de epidemias no PD incluindo a produção e a liberação de conídios de $P$. grisea.

Os conídios de $P$. grisea liberados no ar constituem o principal meio de disseminação (Ou, 1985). As lesões nas folhas superiores produzem conídios para infecção das panículas na época da emissão (Kato, 1974). O estudo da dispersão dos conídios de $P$. grisea e dos fatores que influenciam a infecção nas folhas requerem um método eficiente de coleta de esporos para se obter dados quantitativos. A armadilha volumétrica, 'Rotorod Sampler' desenvolvida por Mectronics Associates Inc, Palo Alto, Califórnia, foi utilizada para a coleta de conídios de $P$. grisea no ar em lavoura de arroz por diversos investigadores (Asai, 1960; Barksdale, 1967; Prabhu \& Wallin, 1971). A utilização de armadilhas vivas para verificar a presença de conídios viáveis no campo foi usada através de plântulas de milho (Zea mays L.) como indicadora de conídios viáveis de Bipolaris maydis (Nisik. \& Miyake) Shoemaker [sinônimos: Helminthosporium maydis Nisikado \& Miyake)] (Wallin \& Loonan,1972).

No presente trabalho, foram realizadas investigações objetivando quantificar os conídios liberados no ar durante a emissão de panículas e formação de grãos e determinar a quantidade de conídios viáveis com potencial para causar infecção nas folhas de arroz no plantio direto e convencional.

\section{MATERIAL E MÉTODOS}

Os experimentos de campo, realizados para estudar a influencia de práticas culturais sobre a brusone nas folhas e nas panículas nos sistema de PD na palha e convencional (PC), foram utilizados para a quantificar a produção de conídios de $P$. grisea. Os experimentos foram conduzidos com as cultivares Primavera e Carajás na safra 1998/1999, com área de $1.344 \mathrm{~m}^{2}$, em cada sistema de plantio e, repetidos na safra 1999/2000, com área de $448 \mathrm{~m}^{2}$ por sistema de plantio, na Fazenda Capivara, Embrapa Arroz e Feijão.

\section{Armadilhas volumétricas}

Foram instaladas duas armadilhas volumétricas Rotorod Sampler do tipo I fixo, uma na área do experimento de PD e outra no PC, realizados em duas safras consecutivas (1998/1999 e 1999/2000) ambas em parcelas da cultivar Primavera, por ser a cultivar mais suscetível. Com o objetivo de quantificar a liberação dos conídios de $P$. grisea, no PD em comparação ao PC, os conídios foram coletados na safra 1998/1999 durante cinco dias (96 e 100 dias após o plantio, DAP), nos estádios entre grão pastoso e maduro e na safra 1999/2000 durante 12 dias (62 até 77 DAP), nos estádios de emborrachamento final a grão leitoso.

A armadilha foi operada em um período de $2 \mathrm{~h}$, entre 9:00 e 11:00 h da manhã. Os bastões, após esse período, foram retirados e levados ao microscópio óptico (40×) para a contagem do número de conídios de $P$. grisea. Esses dados foram utilizados para determinar a quantidade de conídios por volume (litro/min) de ar através da fórmula $\mathrm{RPM} \times \mathrm{K} \times$ $\mathrm{T}$, onde RPM é a rotação por minuto e $\mathrm{K}$ uma constante, determinada de acordo com o tipo de coletor utilizado e, T é o período de funcionamento no campo (Edmonds, 1972).

A quantidade de conídios de $P$. grisea coletados por sistema de plantio foi submetido ao teste T. A análise de regressão foi feita entre quantidade de conídios liberados com o tempo (dias após o plantio) e com a precipitação pluviométrica $(\mathrm{mm})$ diária durante o dia de exposição, com as temperaturas máxima e mínima diárias $\left({ }^{\circ} \mathrm{C}\right)$ e umidade relativa $(\%)$.

\section{Armadilhas vivas}

Objetivando quantificar os conídios viáveis que possuem potencial para causar infecção em novas folhas, as bandejas com as plantas de arroz das cultivares Carajás e Primavera foram expostas no campo, como armadilhas vivas. Para o semeio foram utilizadas bandejas (30 x $10 \times 15 \mathrm{~cm})$ contendo $3 \mathrm{~kg}$ de solo adubado com $5 \mathrm{~g}$ da fórmula 4-30-16, $1 \mathrm{~g}$ de sulfato de zinco e $2 \mathrm{~g}$ de sulfato de amônio, com oito sulcos e 80 sementes. Foi realizado o desbaste dez dias após a semeadura, mantendo-se dez plantas por sulco, e uma adubação de cobertura com $2 \mathrm{~g}$ de sulfato de amônio. As exposições das armadilhas vivas foram realizadas na fase vegetativa de 48 até 78 DAP do experimento de campo, na safra 1999/2000. As bandejas contendo plantas com 25 dias de idade, uma de cada cultivar, foram expostas em suas 
respectivas parcelas no campo no PD e PC, por $48 \mathrm{~h}$. Seguido este período as bandejas foram mantidas por $24 \mathrm{~h}$ em câmara úmida com temperaturas variando de 20 a $25^{\circ} \mathrm{C}$ e, posteriormente, transferidas para casa de vegetação por sete dias. A avaliação da severidade da brusone nas folhas baseouse na porcentagem de área foliar afetada pela doença em 40 plantas por bandeja, utilizando uma escala de 10 graus $(0 \%$, $0,5 \%, 1 \%, 2 \%, 4 \%, 8 \%, 16 \%, 32 \%, 64 \%, 82 \%$ de área foliar afetada) de acordo com Notteghem (1981).

Os dados de severidade por cultivar e por sistema de plantio foram submetidos ao teste de t ao nível de 5\% de probabilidade. A análise de regressão foi feita entre a severidade da brusone nas folhas e a precipitação pluviométrica (mm) acumuladas nos dois dias de exposição, e outros fatores climáticos como citado no item anterior. A análise de correlação foi feita entre a severidade da brusone nas folhas e entre sistemas de plantio para cada cultivar.

\section{RESULTADOS E DISCUSSÃO}

\section{Armadilhas volumétricas}

Na safra 1998/1999 o número de conídios $P$. grisea coletados entre o estádio de grão pastoso e de panículas maduras aumentou linearmente com o tempo tanto no PD como no PC (Figura 1). A taxa de aumento de conídios coletados, nos cinco dias de avaliação, indicada pelos valores de $b$ no PC $(b=0,1949)$ e no PD $(b=0,0862)$, diferiram significativamente pelo tese de $\mathrm{t}(5,04, \mathrm{P} \leq 0,01)$. No campo, a severidade da brusone nas panículas no campo foi maior no PC (20,29\%) em relação ao PD (12,58\%).

Na safra 1999/2000, o número de conídios coletado aumentou de maneira exponencial iniciando na fase do emborrachamento até estádio de grão leitoso (Figura 2), sendo maior no PC, confirmando os resultados do ano anterior. Os estudos realizados em outras condições edafoclimáticas mostraram que os períodos chuvosos interferem na quantidade de conídios liberados no ar (Kingsolver et al., 1984; Ou, 1985).

O número de conídios de $P$. grisea por litro de ar/ minuto variou de 0,054 a 0,068 no PD e de 0,068 a 0,091 no PC, na fase vegetativa (Figura 3). Considerando as médias dos 12 dias de exposição da armadilha, a quantidade de conídios coletados foi significativamente superior no PC em comparação ao $\mathrm{PD}(\mathrm{t}=3,53 ; \mathrm{P} \leq 0,01)$. O número de conídios coletados foi relativamente baixo em alguns dos dias de exposição, entre 68 e 76 DAP. Verificou-se uma relação inversa entre a precipitação pluviométrica e a quantidade de conídios coletados nos dois sistemas de plantio. O número de conídios coletados diminuiu de maneira exponencial com o aumento da precipitação pluviométrica, durante o período de exposição (Figura 4), embora outros fatores possam interferir na produção e liberação dos conídios. As temperaturas máximas e mínimas apresentadas durante o período de coleta não foram correlacionadas com o número de conídios coletados, indicando que a influência da chuva na severidade da brusone nas panículas foi maior do que temperatura máxima e mínima. Ahn (1981) demonstrou uma relação quadrática entre a severidade da brusone nas panículas e a precipitação acumulada no período do $5^{\circ}$ ao $9^{\circ}$ dia após o florescimento, indicando que com o aumento da precipitação houve redução na severidade da brusone.

A população de conídios de $P$. grisea atinge altos níveis no início da emissão das panículas, o que contribui para a posterior infecção das panículas, nó, ráquis, pedicelos e grãos (Prabhu et al. 1986). O aumento da brusone nas panículas sob condições de estresse hídrico devido ao acúmulo de nutrientes nas ramificações das panículas (Prabhu \& Morais, 1986), explica parcialmente a maior produção de conídios no sistema PC. Em plantas com sintomas de deficiência hídrica as lesões produzem de três a cinco vezes mais conídios que em plantas não sujeitas a estresse (Gill \& Bonman, 1988). A relação entre a severidade da brusone nas folhas e nas panículas é positiva e indicando a possível

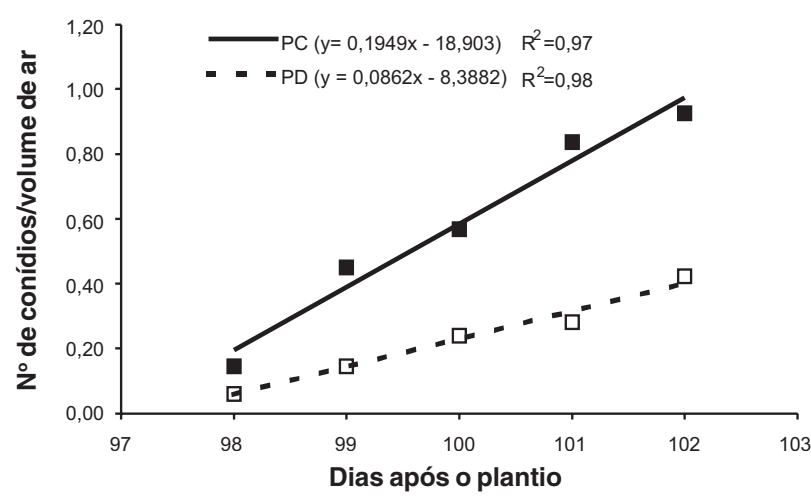

FIG. 1 - Número de conídios de Pyricularia grisea coletados com armadilha volumétrica, na fase de desenvolvimento da panícula de arroz (Oryza sativa) em dois sistemas de plantio na safra 1998/ 99 (em exposição de $2 \mathrm{~h}$ por dia, cada ponto representa uma data de exposição). As diferenças ente os valores de 'b' são significativos pelo teste de $\mathrm{t}$, ao nível de $1 \%$ de probabilidade.

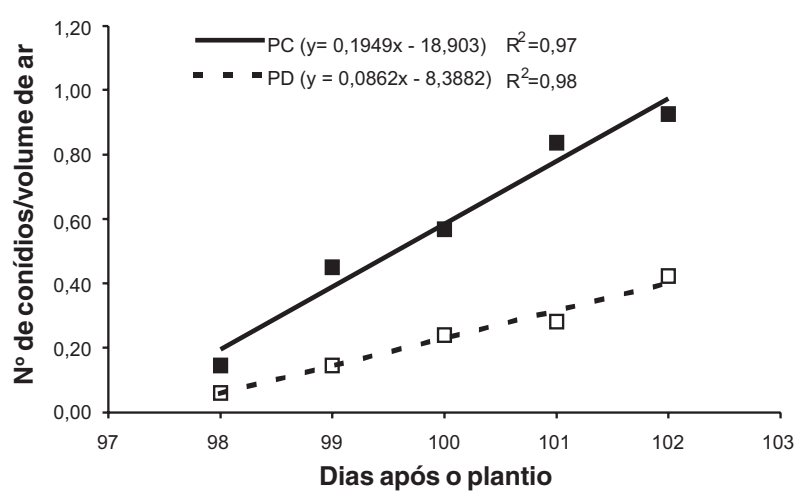

FIG. 2 - Conídios de Pyricularia grisea coletados com armadilha volumétrica, no plantio direto (PD) e convencional (PC), na safra 1999/2000 de arroz (Oryza sativa) (em exposição de 2 h por dia). 


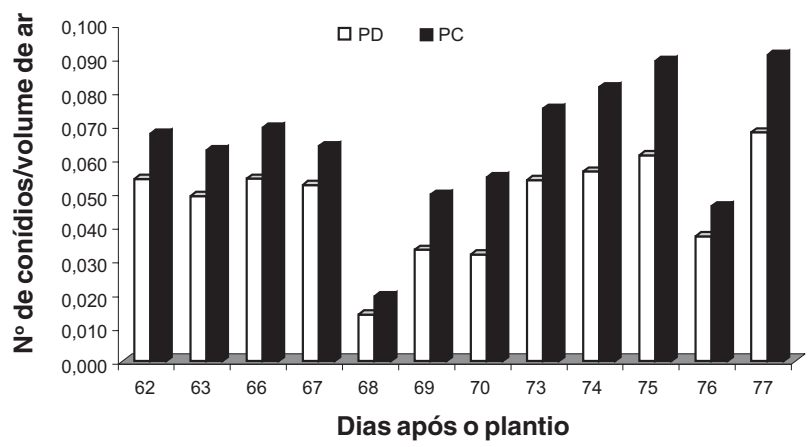

FIG. 3 - Número de conídios de Pyricularia grisea coletados com armadilha volumétrica, na safra 1999/2000 no plantio direto (PD) plantio convencional (PC) de arroz (Oryza sativa). (em exposição em $2 \mathrm{~h}$ por dia).

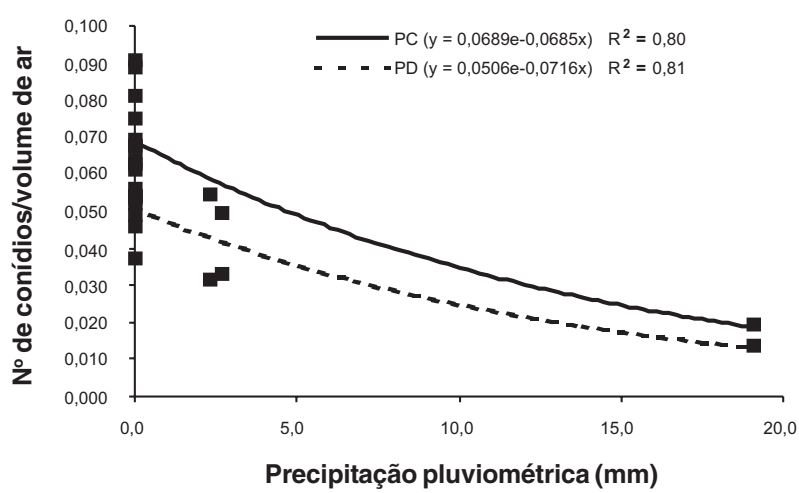

FIG. 4 - Relação entre o número de conídios de Pyricularia grisea coletados com a armadilha volumétrica e a precipitação pluviométrica, no plantio direto (PD) e no convencional (PC), na safra 1999/2000 de arroz (Oryza sativa). (em exposição de $2 \mathrm{~h}$ por dia).

participação dos conídios produzidos nas lesões esporulativas nas folhas na infecção das panículas (Prabhu et al., 1996). Os conídios liberados no ar constituem-se em um meio importante de dispersão de inóculo de $P$. grisea, embora as sementes e os restos culturais sejam também fontes de infecção primária. A maioria dos conídios é liberada durante a noite, no período das 2:00 as 6:00 h da manhã e o segundo aumento máximo foi verificado $12 \mathrm{~h}$ após a chuva $(\mathrm{Ou}$, 1985). Barksdale \& Asai (1961), observaram a periodicidade diurna da liberação de conídios de $P$. grisea. No presente estudo os bastões foram expostos somente por $2 \mathrm{~h}$, no intervalo de 9:00 as 11:00 h da manhã, sem levar em consideração o máximo da liberação de conídios. A exposição dos bastões por mais de $12 \mathrm{~h}$ dificulta a leitura devido ao grande número de conídios, bem como pela sobreposição de outras partículas no bastão. A armadilha volumétrica Rotorod Sampler apresentou elevada eficiência na detecção de conídios de $P$. grisea liberados no ar em 2 h de exposição no campo, e poderá ser utilizada em estudos posteriores de produção e liberação de conídios de $P$. grisea, para comparar a quantidade de conídios em diferentes sistemas de plantio.

\section{Armadilhas vivas}

Os resultados da severidade da brusone nas folhas nas armadilhas, realizada aos nove dias da exposição, encontram-se na Tabela 1. Considerando os 16 dias de exposição das bandejas, dos 48 aos 78 DAP, a cultivar Carajás apresentou severidade da brusone variando de 0,76 a $10,7 \%$ e Primavera de 2,8 a 19,0\% no PD. A severidade da brusone foi maior no PC, variando de 0,36 a $21,0 \%$ para a cultivar Carajás e de 3,9 a 46,7\% para Primavera. No PD, as cultivares diferiram significativamente pelo teste de $\mathrm{t}\left(2,79^{*}\right)$. Entretanto, as cultivares não diferiram significativamente no PC $\left(0,86^{\text {ns }}\right)$. Considerando as diferenças em relação às médias de severidade da brusone nas folhas entre o sistema de plantio por cultivar, tanto Carajás (4,37**) quanto Primavera $(6,99 * *)$ apresentaram diferenças significativas, sendo maior no PC. Embora a duração do orvalho seja pré-requisito para infecção, esse efeito foi reduzido sobre a infecção através do período adicional de incubação em casa de vegetação.

A correlação entre a severidade da brusone nas folhas nas armadilhas no PD e no PC, foram positivas, paras as cultivares Carajás $(\mathrm{r}=0,91 ; \mathrm{P} \leq 0,01)$ e Primavera $(\mathrm{r}=0,96$, $\mathrm{P} \leq 0,01)$, sendo os níveis da severidade da doença menores no PD.

A relação entre a severidade da brusone nas folhas

TABELA 1 - Severidade da brusone nas folhas de plantas de arroz (Oryza sativa) cultivadas em bandejas e expostas no campo, por um período de $48 \mathrm{~h}$, no plantio direto e no convencional, na safra 1999/2000

\begin{tabular}{|c|c|c|c|c|}
\hline \multirow{3}{*}{$\begin{array}{l}\text { Data de } \\
\text { exposição } \\
\text { (DAP) }\end{array}$} & \multicolumn{4}{|c|}{ Severidade da brusone nas folhas $(\%)$} \\
\hline & \multicolumn{2}{|c|}{ Plantio direto } & \multicolumn{2}{|c|}{ Plantio convencional } \\
\hline & Carajás & Primavera & Carajás & Primavera \\
\hline 48 & 8,05 & 14,60 & 17,98 & 47,10 \\
\hline 50 & 1,20 & 2,80 & 0,78 & 3,90 \\
\hline 52 & 7,80 & 12,70 & 14,30 & 38,15 \\
\hline 54 & 5,30 & 7,60 & 2,00 & 9,15 \\
\hline 56 & 3,20 & 4,80 & 1,84 & 7,26 \\
\hline 58 & 9,30 & 14,30 & 16,70 & 37,15 \\
\hline 60 & 4,80 & 6,30 & 9,26 & 8,60 \\
\hline 62 & 7,90 & 13,60 & 18,90 & 44,05 \\
\hline 64 & 7,10 & 12,10 & 13,03 & 32,05 \\
\hline 66 & 3,30 & 4,00 & 1,60 & 6,15 \\
\hline 68 & 7,00 & 12,10 & 17,10 & 36,71 \\
\hline 70 & 0,76 & 1,40 & 0,36 & 4,49 \\
\hline 72 & 7,40 & 13,05 & 7,90 & 35,60 \\
\hline 74 & 8,90 & 16,07 & 16,90 & 39,70 \\
\hline 76 & 10,70 & 19,01 & 19,70 & 44,90 \\
\hline 78 & 9,50 & 17,03 & 21,00 & 46,70 \\
\hline Média* & 6,38 & 10,71 & 11,20 & 27,60 \\
\hline
\end{tabular}

*As médias diferem pelo teste 't' no PD entre cultivares $(2,79 *)$, entre sistema de plantio tanto para cultivar Carajás $(\mathrm{t}=4,37 * *)$ como para Primavera $\left(6,99^{* *}\right)$, ao nível de $5 \%$ (*)e de $1 \%$ (**). As severidade médias entre cultivares não diferiram significativamente pelo teste de $\mathrm{t}\left(0,86^{\mathrm{ns}}\right)$ dentro do $\mathrm{PC}$. 
nas armadilhas com a precipitação pluviométrica nas duas cultivares e nos dois sistemas de plantio são apresentadas na Figura 5. A severidade da brusone nas folhas das armadilhas diminuiu de maneira exponencial com o aumento da precipitação pluviométrica em ambas as cultivares. O efeito da precipitação pluviométrica sobre a redução da severidade da brusone nas folhas foi maior nas plantas da cultivar Carajás, provavelmente devido ao menor grau de suscetibilidade à brusone. Estes resultados estão de acordo com Kim, (1994) que a quantidade de chuvas reduz grandemente a brusone nas folhas. As temperaturas máximas, mínimas e médias e a umidade relativa do ar, durante o período de exposição no campo, não foram correlacionadas com a severidade da brusone nas folhas.

O número de infecções nas folhas é influenciado pelo grau de suscetibilidade da cultivar, condições climáticas além da quantidade de conídios de $P$. grisea viáveis (Ou, 1985). A maior parte das informações existentes, foi obtida com base em estudos sob condições controladas. Entretanto, no presente trabalho, o monitoramento de conídios de $P$. grisea no campo, utilizando armadilhas vivas mostrou ser um método viável para a análise e quantificação de alguns fatores que influenciam a produção e a liberação de conídios e a infecção das plantas por $P$. grisea. Tanto as armadilhas vivas como as volumétricas permitiram determinar menor quantidade de conídios no PD, que permitiram explicar os menores níveis da brusone nas folhas e panículas neste sistema de plantio.
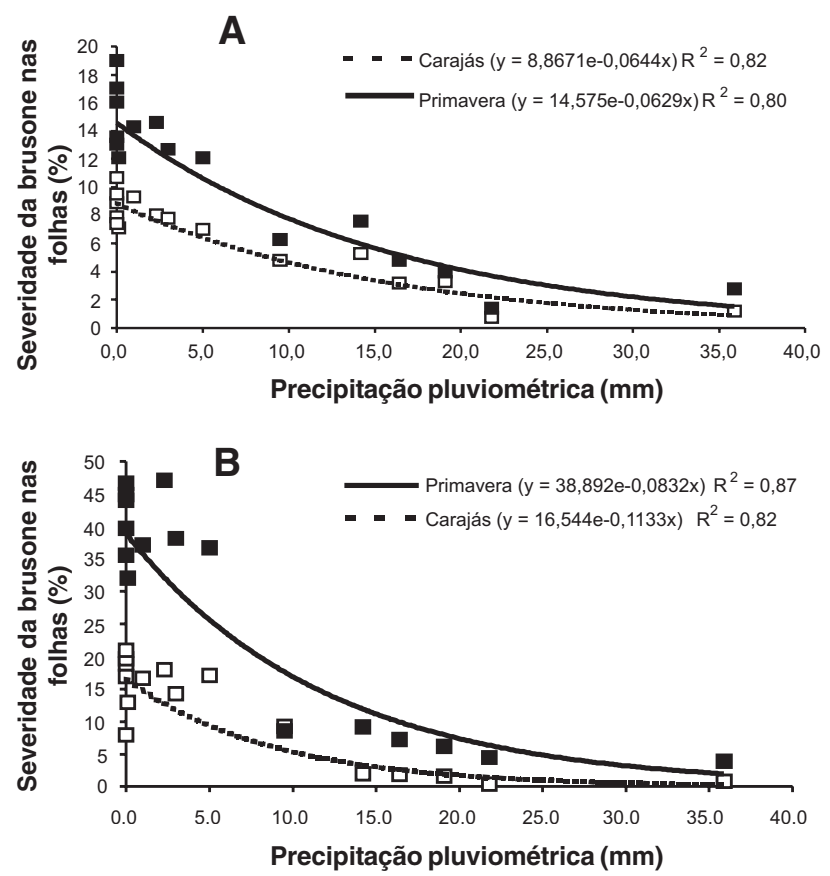

FIG. 5 - Relação entre precipitação pluviométrica e a severidade da brusone nas folhas da armadilha viva, no plantio direto (A) e no convencional (B) de arroz (Oryza sativa), na safra 1999/2000.

\section{REFERÊNCIAS BIBLIOGRÁFICAS}

AHN, S.W. Slow blasting resistance. In: Proceedings of the symposium on rice resistance to blast. Montpellier, France. IRATGERDAT. 1981. pp.343-370.

ASAI, G.N. Intra-and inter-regional movement of uredospores of black stem rust in Upper Mississippi River Valley. Phytopathology 50:535-541.1960.

BARKSDALE, T.H. Spread of rice blast in small fields. Plant Disease Reporter 51:243-247. 1967.

BARKSDALE, T.H. \& ASAI, G.N. Diurnal spore release of Pyricularia oryzae from rice leaves. Phytopathology 51:313-317. 1961.

EDMONDS, R.L. Collection efficiency of rotorod samplers for sampling fungus spores in the atmosphere. Plant Disease Reporter 56:704-708. 1972.

FERNANDES, J.M.C. As doenças das plantas e o sistema plantio direto. Revisão Anual de Patologia de Plantas 5:317-352. 1997.

GASSEN, D. \& G. GASSEN. Plantio direto: O caminho do futuro. Passo Fundo (RS): Aldeia Sul. 1996.

GILL, M.A. \& BONMAN, J.M. Effects of water deficit on rice blast. I. Influence of water deficit on components of resistance. Journal of Plant Protection in the Tropics 5:61-66. 1988.

KATO, H. Epidemiology of rice blast disease. Review of Plant Protection 7:1-20. 1974.

KIM, C.K. Blast management in high input, high potential temperature rice ecosystem. In: Zeigler, R.S., Leong, S.A. \& Teng, P.S. (Eds.) Rice blast disease. Wallingford. CAB International. 1994. pp.451-464.

KINGSOLVER, C.H., BARKSDALE, T.H. \& MARCHETTI, M.A. Rice blast epidemiology. University Park: Pennsylvania State University, Bulletin, 853, 1984.

NOTTEGHEM, J.L. Cooperative experiment on horizontal resistance to rice blast. In: Blast and upland rice: report and recommendation from the meeting for international collaboration in upland rice improvement. Los Baños: IRRI, 1981. pp.43-51.

OU, S.H. Rice disease. 2.ed. Kew: Commonwalth Mycological Institute, 1985.

PRABHU, A.S.; FILIPPI, M.C. \& ZIMMERMANN, F.J.P. Genetic control of blast in relation to nitrogen fertilization in upland rice. Pesquisa agropecuária brasileira 31:339-347. 1996.

PRABHU, A.S., STEINMETZ, S. \& ZIMMERMANN, F.J.P. Identificação de fatores climáticos favoráveis às infecções de brusone nas folhas em condições de arroz de sequeiro. Fitopatologia Brasileira 11:324. 1986. (Resumo)

PRABHU, A.S. \& MORAIS, O.P. Rice blast management in upland rice in Brazil. In: Shilder, F.J. \& Mendoza, C.V. (Eds.) Progress in upland rice research. Manila, IRRI, 1986. pp.382-394.

PRABHU, A.S. \& WALLIN, J.R. Influence of temperature and light on spore production of Puccnia graminisf. sp. tritici. Phytopathology 61:170-171. 1971.

WALLIN, J.R. \& LOONAN, D.V. Live plant detection of airborne spores of Helminthosporium maydis race T in the field. Plant Disease Reporter 56:659-661. 1972.

WEBSTER, R.K. \& GUNELL, P.S. Compendium of rice diseases. Minnesota: APS Press. 1992. 